\title{
Diffraction or reflection? Sketching the contours of two methodologies in educational research
}

Vivienne Bozalek and Michalinos Zembylas

\begin{abstract}
Internationally, an interest is emerging in a growing body of work on what has become known as 'diffractive methodologies' drawing attention to ontological aspects of research. Diffractive methodologies have largely been developed in response to a dissatisfaction with practices of 'reflexivity', which are seen to be grounded in a representational paradigm and the epistemological aspects of research. While work on 'reflexivity' and 'critical reflection' has over the years become predominant in educational and social science research methodology literature, our reading indicates that there is still important conceptual work to be done putting these two practices - reflection and diffraction - in conversation with each other and exploring their continuities and breaks as well as examining the consequences for research methodologies in education. This article raises important questions about how the concepts of diffraction and reflection are defined and understood and discusses the methodological implications for educational research.
\end{abstract}

\section{Introduction}

Dissatisfied with epistemological practices of reflexivity grounded in representationalism, scholars immersed in feminist science studies began to raise questions about the theoretical assumptions and consequences of reflexivity. Haraway (1997), a pioneer in these debates, proposed the notion of diffraction as an alternative to reflexivity. As she expressed her misgivings at the time:

Reflexivity has been much recommended as a critical practice, but my suspicion is that reflexivity, like reflection, only displaces the same elsewhere, setting up worries about copy and original and the search for the authentic and really real. (1997, p. 16).

Haraway suggested instead that, '[w]hat we need is to make a difference in material-semiotic apparatuses, to diffract the rays of technoscience so that we get more promising interference patterns on the recording films of our lives and bodies' (1997, added emphasis). Thus diffraction for Haraway was suggested as a metaphor and a strategy for making a difference in the world that breaks with self-reflection and its epistemological grounding, which she regarded as problematic as it lures us into a reductionist way of thinking about things and words (Haraway, 2000). The Cartesian belief that we have direct access to representations or our thoughts and that we do not 
have access to the outside or material world is also predicated on the idea of ourselves as independent individuals who are knowing

subjects (Rouse, 1996).

The notion of diffraction has been taken forward in the work of Barad (2007, 2010, 2014, 2015) who does not only regard diffraction as an optical metaphor, but also as a method and a practice that pays attention to material engagement with data and the 'relations of difference and how they matter' (Barad, 2007, p. 71). Diffraction is understood by both Barad and Haraway as a process of being attentive to how differences get made and what the effects of these differences are. Barad's notion of diffraction is derived from the physical phenomenon of diffraction which she extends to other forms of knowledge production. ${ }^{1}$ Diffraction from her perspective can be used to acknowledge the influential role of the knower in knowledge production and particularly how we learn about 'material configurations of the world's becoming'(p. 91). For Barad, diffraction is a useful tool highlighting the entanglement of material-discursive phenomena in the world. Diffraction is thus predicated on a relational ontology, an ongoing process in which matter and meaning are coconstituted.

Our point of departure in this essay is Haraway's and Barad's suggestion that diffraction constitutes an alternative methodology to reflexivity. From their perspective, reflexivity remains caught up in sameness because of its mirroring of fixed positions, whereas diffraction is specifically attuned to differences and their effects in knowledge-making practices. In addition, diffraction is not only epistemic, but also ontological and ethical (Barad, 2007, 2014). We, therefore, consider in this paper what the methodological implications of both this metaphor and method would be for doing research in education. We acknowledge that there have already been important efforts so far to theorize what a diffractive analysis would imply for research in education (e.g. see Davies, 2014a, 2014b; Hoel \& van der Tuin, 2012; Hultman \& lenzTaguchi, 2010; Jackson \& Mazzei, 2012; Juelskjaer, 2013; lenz Taguchi, 2012; lenz Taguchi \& Palmer, 2013; Palmer, 2011). our analysis joins and builds on these efforts, focusing in particular on how these two practices reflection and diffraction - differ from each other and/or intersect and what consequences such understandings might have for research methodology in education.

In light of the prominent influence of the concepts of 'reflection', 'reflexivity', 'critical reflection' and 'reflective practice' in the fields of education, professional practice and lifelong learning in recent decades (e.g. Bradbury, Frost, kilminster, \& Zukas, 2010; Brookfield, 1995; Fook, 2002; Fook \& Gardner, 2007; korthagen, kessels, koster, lagerwerf, \& Wubbels, 2001; lyons, 2010; Pollard, 2002; Zeichner \& liston, 1996), we wonder: How is diffraction, as a concept/metaphor and a method, really different from reflection? Are there any points of convergence and divergence between these two concepts/practices/ methods? What are the epistemological, ontological, ethical and methodological assumptions in which diffractive analysis and reflexive methodology are grounded? We want to state upfront that our objective here is not to read one practice against the other - which would amount to what sedgwick (2003) called 'paranoid' reading - nor to argue that diffraction is necessarily 'better' and can 'save' us; we are afraid that such a practice would reiterate the binaries that need to be overcome. Rather, we are interested in putting the two practices in conversation, delving more deeply into their continuities and breaks. 
In the first part of the paper, we discuss the concept of reflection, its different meanings and the epistemological, ontological and methodological premises on which it is grounded. We do the same for diffraction and then discuss their convergences and divergences, emphasizing in particular the historical continuity between reflection and diffraction and at the same time the break that has come with diffractive methodology. To concretize these convergences and divergences, we provide examples of how we have used both a diffractive and reflexive methodology in reading groups which are part of research projects in which we are co-investigators. The paper ends with a brief discussion on the methodological implications of this analysis for educational research.

\section{Reflection - What is it?}

First of all, the visual metaphor of reflection is certainly not new, but rather it has been used since ancient Greek philosophy (Haraway, 1997). Reflection as the physical phenomenon of mirroring has been used as a metaphor to express an inner mental activity in which someone is taking a 'step back' and looking into his or her self for the purpose of thinking about one's life and perhaps changing it (Barad, 2007). In late and advanced modernity, 'reflexivity' has become a major concept in sociological discussions expressing the ability and practice of a person to change his or her life in response to knowledge about one's social circumstances. The work undertaken by sociologists like Beck and Giddens has become a central point of reference in debates about how reflexivity is relevant to social transformation. The concept of reflexivity has grown to encompass different meanings among different research traditions and disciplines, often lacking a distinction among the different terms used such as reflection, reflexivity and critical reflection, to name a few. To show this, we briefly discuss reflexivity in sociology, social work and education and then focus more specifically on reflexivity in research methodology2.

To begin with the sociological tradition, Giddens and Beck's work is based on the notions of an individualization thesis - the weakening of traditional customs and the rise of individual agency of personal choice and agency. There are many assumptions in their work about late modernity and about how life has changed (particularly family life) and become more democratic. For Beck (1992, 1994), reflexivity is linked to the process with which individuals reflect on the threats posed to the self by risks in modern societies. Beck makes a distinction between 'reflection' - which focuses on the knowledge gained - and 'reflexivity' - which focuses on the practices that individuals use for the process of self- confrontation. Giddens $(1990,1991)$ defined reflexivity as the ability to act critically in the world in ways that reduce struggles over power and politics. His theory of reflexive self has been criticized because social problems are presented as the consequences of poor decisions, rather as being influenced by social and political forces. Another criticism posed in sociological debates over the notion of reflexivity, is how this concept is discussed mostly in cognitive terms, ignoring the role of emotions (D'Cruz, Gillingham, \& Melendez, 2007; Holmes, 2010). similar to Beck and Giddens, Archer $(2003,2007,2010)$ locates reflexivity in late modernity but departs from Beck and Giddens in that she considers reflexivity as mediating between structure and agency and as entailing emotions as well.

In their review of the social work literature on the different meanings of 'reflexivity', D'Cruz et al. (2007) identify three variations. It is valuable to briefly revisit each variation because they show 
precisely the different nuances as well as the epistemological and ontological assumptions embedded in each manifestation. The first variation regards reflexivity as an individual's response to his or her social circumstances; Giddens' and Beck's work are included in this variation. This definition of reflexivity emphasizes the ability of the individual to make choices, hence individuals are considered responsible for problems they experience. Definitions in this variation, suggest D'Cruz and her colleagues, assume that reflexivity is developed as a skill which can be used to master the forces that shape one's life; reflexivity, then, is understood as a competence that can be taught and is offered as a means of emancipation and self-actualization.

The second variation defines reflexivity as an individual's self-critical approach that questions how knowledge is generated and how power relations influence the process of knowledge production. Feminist research in particular has developed and explored notions of 'reflexivity'and 'critical reflection' to highlight the multiple interrelations between power and knowledge in the research process. For example, Harding's (1996) concept of 'strong objectivity' recognizes and responds to the entanglement of power and knowledge in the research process. In this regard, reflexivity and critical reflection constitute practices of interrogating knowledge, including the role of the researcher's own subjectivities. Feminist researchers have applied the practices of reflexivity and critical reflection to interrogate reflexivity itself (Daley, 2010). As Daley explains, feminist research has particularly examined the role of the researcher in addressing methodological dilemmas of interpretation and representation, calling attention to emotions, relationality, discourse and women's bodies (Gray, 2008; Holmes, 2010).

Finally, the third variation is aligned to the second variation in that it is based on a critical examination of the factors that influence knowledge production (D'Cruz et al., 2007). What it adds, according to D'Cruz and her colleagues, is the acknowledgment of the role of emotions in the process of reflexivity and the 'emotionalization'of reflexivity, as Holmes (2010) calls it. By using this term, Holmes refers not only to the theoretical attention to emotion, but also to the exploration of how individuals can increasingly draw on emotions in assessing themselves and their lives. Holmes and others (e.g. Zembylas, 2014) argue that emotions are crucial to how the social and the political are reproduced through power relations.

A broad overview of the increasing work on the notion of 'teacher reflection'in the field of education (e.g. see edwards \& Thomas, 2010) suggests that reflexive processes are usually directed either towards the self and its rational choices (the first variation in D'Cruz et al.'s terms) or towards knowledge and its social production within power relations (the second and third variations). This analytical distinction is indicative of the differential emphasis and meaning placed in each case; the former focuses on the self as the locus of reflection, while the latter focuses on how relations of power operate and what consequences they have not only for the self-reflexive process and the knowledge production, but also for thepossibilities to invoke change. Also, in theformer, reflexivity is defined as a competency, a set of skills and abilities to look into one's self and make rational choices (e.g. see Moon, 1999). In this case, reflexivity is a 'project of the self' (elliott, 2002) that depends upon the individual ability of the teacher to employ professional judgement and make informed choices. not surprisingly, then, reflexivity is neatly aligned in a judgmental framework (Davies et al., 2013) that equates with what Deleuze (1988) calls moralism, that is, a system that 
judges against a set of ideals, rather than an ethics of immanence in life (Davies \& Gannon., 2013) or a moment-by-moment ethics of how, in specific ways, things come to matter in an encounter (Davies et al., 2013). This 'individualistic' theory of teacher reflection reduces reflexivity into a collection of competencies, attributes and qualities to be attained and undermines the ideological context and the power structures in which teacher reflection takes place (edwards \& Thomas, 2010). edwards and Thomas (2010) as well as other scholars in education (e.g. Fendler, 2003; Zembylas, 2014) criticize the key tenets of reflective thinking in a number of educational texts, because they are presented in a sterile way and more often than not omit critical orientations, ideological aspects and the politics of emotion. 3

The notion of 'critical reflection', then, has emerged as an approach that unpacks how power relations influence the processes of knowledge production in teaching and learning, including the process of reflexivity itself (Harrison \& lee, 2011). Mezirow (1990) acknowledged that there is more to reflection than simply thinking about experiences, pointing out that critical reflection involves a critique of our held assumptions and values. Brookfield (1995) used the term 'critical reflection' to distinguish the difference with instrumental reflection, suggesting that critical reflection involves critical thinking, which links personal experience with social and power arrangements. Fook (2002) added that critical reflection involves thinking about one's practice and critically deconstructing how we have developed these skills and how some of these discourses might work against us (see also, Fook \& Gardner, 2007).

Finally, concerning research methodology and more specifically qualitative research, reflexivity has been defined as a generalized practice in which researchers attempt to acknowledge their influence on research (Gentles, Jack, nicholas, \& Mckibbon, 2014; Mruck \& Mey, 2007). The idea of reflexivity in qualitative research, according to these authors, has largely evolved from methodological critiques regarding problems of representation in research, such as claims of objectivity and relativism and the influence of the researcher in what is being researched. They suggest that the general objective of reflexivity is to increase transparency and trustworthiness in research, yet there have been several criticisms pointing out either the dangers of excessive reflexivity, the uncritical adoption of it and its consequences in really producing better research (Pillow, 2003; schneider, 2002) or criticisms about the inadequacy of reflexive methodology because it involves ambivalent practices (Davies et al., 2004) and produces partial accounts (Gentles et al., 2014).

\section{Diffraction - What is it?}

Haraway $(1992,1997)$ first began to consider how reflexivity may be inadequate for bringing the self into visibilityin relation to knowledgethat is situated(Haraway, 1991). Haraway's(1991) notion of situated knowledges, by which she meant a particular and embodied perspective of the knower and her/his social networks, was written in response to Harding's $(1991,1996)$ notions of critical/strong reflexivity or strong objectivity, which require a critical interrogation of the effects of one's own location on the production of knowledge. Both Haraway and Harding were critical of the limits of scientific universal views of the world. In situated knowledges and strong reflexivity, the knower's social location and subjective embodiment is seen as having a direct effect on the knowledge produced, and in terms of feminist reflexivity, subjugated standpoints are seen to produce more accurate accounts of knowledge due to their vantage point. 
The concern with situated knowledges was seen as a transitional phase where Haraway was still writing about reflexive knowledge, which was located in a representational model, before she moved her attention to the promises of diffraction as a methodology in her later works, 'The Promises of Monsters' (1992) and Modest Witness@Second-Millennium.FemaleMan@-Meets-OncoMouse ${ }^{\mathrm{TM}}$ (1997). In these works, she eschews reflexivity as a means for achieving strong objectivity and situated knowledges, seeing possibilities instead in the metaphor of diffraction (Campbell, 2004). What attracted Haraway to the notion of diffraction is the affordance it provides for patterns of difference and heterogeneity through interference rather than sameness - which reflection and reflexivity tend to signify. Haraway (1992) initially defined diffraction as 'a mapping of interference, not of replication, reflection, or reproduction. A diffraction pattern does not map where differences appear, but rather maps where the effects of difference appear'(p.300).

The possibility of including non-humans together with humans was another advantage of using diffraction rather than reflection. For example, Haraway explains how the notion of diffraction is a useful one when considering feminist theorist Trinh Minh-ha's inappropriate/d others'for rethinking difference regarding social relationality among humans and between human and nonhumans:

The term 'inappropriate/d others' can provoke rethinking social relationality within artifactual nature-which is, arguably, global nature in the 1990s. Trinh Minh-ha's metaphors suggest another geometry and optics for considering the relations of difference among people and among humans, other organisms, and machines than hierarchical domination, incorporation of parts into wholes, paternalistic and colonialist protection, symbiotic fusion, antagonistic opposition, or instrumental production from resource. Tropically, for the promises of monsters, the first invites the illusion of essential, fixed position, while the second trains us to more subtle vision. (1992, p. 296)

From this perspective difference is seen in an affirmative light, as a tool of creativity rather than as separation and lack. Difference here is not positioned as the opposition to sameness - but is also incorporated into the self as difference within and seen as a means of becoming. Diffractive patterns which reveal that there is light in darkness and dark in lightness are similarly fluid and provide an understanding of how binaries can be queered, and how differences exist both within and beyond boundaries (Barad, 2014).

Barad (2007) builds on Haraway's ideas of diffraction as a metaphor, trope or figuration. she proposes diffraction as a methodological approach focusing on difference and the entanglement of matter and meaning, using ideas from niels Bohr's quantum physics. she does not only see diffraction or interference as a metaphor or as a category but also as a physical phenomenon which is part of wave behaviour - whether it is light, water or sound waves. Diffraction is where waves 'combine when they overlap and the apparent bending and spreading out of waves when they encounter an obstruction' (Barad, 2007, p. 28). In combining, waves can be amplified by being superimposed upon one another. Barad uses this physical process of diffraction as a methodology which engages affirmatively with difference. 
Barad (2014) thus posits that diffraction is more than merely a metaphor - it is a method or methodology. she notes that it is not just quantum physics which has played a part in developing diffractive methodology - feminist theorizing about difference has in itself made a significant contribution to its development. In a diffractive methodology, the details of one discipline (in this case quantum physics) are read attentively and with care through another (feminist queer theory) in order to come to more creative insights. Barad proposes a diffractive methodology rather than critique, which she regards as passe (latour, 2004) and a potentially epistemologically damaging process of distancing, othering and putting others down (Juelskjær \& schwennesen, 2012). A diffractive methodology in contrast, is not setting up one approach/text/discipline against another but rather a detailed, attentive and careful reading the ideas of one through another, leading to more generative 'inventive provocations'(Dolphijn \& van der Tuin, 2012, p. 50) and the possibility of a true transdisciplinarity rather than interdisciplinarity. 4 In diffraction, material-discursive phenomena, 5 matter and meaning are seen as entangled. As Barad notes in her interview with Adam kleinman on intra-actions for Mousse magazine, matter is not just things or bodies but 'substance in its iterative intra-active becoming - not a thing, but a doing, a congealing of agency. It is morphologically active, responsive, generative, and articulate. Mattering is the ongoing intra-active differentiating of the world' (kleinman, 2012, p. 76). Barad also equates matter with meaning or sense-making which she refers to as 'mattering' or as 'material-discursive' (Barad, 2007, 2014; kleinman, 2012). For Barad, matter is not just of the head but also of the heart and hands; it has to do with a scholarly engagement with care, social justice and seeing oneself as part of a world. Diffraction is also then about issues of taking responsibility, or as Barad refers to it - response-ability, of a yearning for social justice (Barad, 2007) and towards possible worlds (Haraway, 1997). Diffraction is thus seen as both a process and as a result - ontologically a being and becoming. Barad's approach entails a relational ontology which is not separated from epistemological and ethical domains - she refers to it as an ethico-onto-epistemological approach.

This methodology as described by Barad has been put to creative use by educational theorists and practitioners such as Jackson and Mazzei (2012) who use diffractive methodology to examine the same set of data from different poststructural concepts of Derrida, spivak, Foucault, Butler, Deleuze and Barad herself. lenz Taguchi $(2012,2013)$ has used a diffractive methodology to differently conceptualize early child development and her collaborative data analysis work with her Ph.D. students. Bronwyn Davies (2013) analysed anger using a diffractive methodology at a swedish preschool and Phillips and larson $(2012,2013)$ have used a diffractive methodology to analyse data from a teacher-student writing conference as an entanglement of the discursive and the material. This emerging work of analysing data in educational research highlights that diffractive analysis can make visible new kinds of material-discursive realities that have important epistemological, ontological and methodological consequences. It is to these consequences that we turn in our discussion now.

\section{Reflection and diffraction: continuities and breaks}

For both Haraway and Barad, 'diffractive analysis constitutes an alternative methodology to critical reflection'(lenz Taguchi, 2012, p. 268). Why is this so? Haraway, Barad as well as education 
scholars who have recently used diffractive analysis (e.g. Davies, 2014a, 2014b; Hultman \& lenz Taguchi, 2010; Jackson \& Mazzei, 2012; Juelskjær \& schwennesen, 2012; larson \& Phillips, 2013; lenz Taguchi, 2010, 2012; lenz Taguchi \& Palmer, 2013; Palmer, 2011) argue that reflexivity is not sufficient any more on two important grounds. First of all, as it is suggested, reflexivity starts off with preconceived assumptions of binaries rather than investigating how boundaries or binaries are produced through the methodology itself. In reflexivity, there is a researcher as an independent subject who is actually the locus of reflection, whereas in diffraction there is no such distinction as subjects and objects are always already entangled. Thus, from a diffractive perspective, subjects and objects such as nature and culture are not fixed referents for understanding the other but should be read through one another as entanglements. As Barad puts it unlike methods of reading one text or set of ideas against another where one set serves as a fixed frame of reference, diffraction involves reading insights through one another in ways that help illuminate differences as they emerge: how different differences get made, what gets excluded, and how these exclusions matter. (Barad, 2007, p. 30)

For Barad and Harraway, bodies too are not fixed entities with essences or properties and boundaries, but'material-discursive phenomena'(Barad, 2007, p. 153).

Also, as lenz Taguchi (2012) and Jackson and Mazzei (2012) point out, the perennial goal for interpretation falls into the representational trap of trying to figure out what a subject really means. lenz Taguchi explains that,

As an act of thinking, interpretation in reflexive analysis is about reflecting sameness (as in mirroring), or identifying differences from something previously identified and acknowledged; a thing, an identity, a category, a discursive theme or a subject position. (2012, p. 269)

Reflection remains fundamentally an inner mental activity in which the researcher supposedly takes a step back and reflects at a distance from the outside of the data (Hultman \& lenz Taguchi, 2010). Reflection is thus based on the assumption of an 'I' who is different and exterior to that which is conceptualizing, an 'I' who is separate from the world (lenz Taguchi, 2010). The slip into the subject 'I' is important in understanding reflection and diffraction, since in the latter there is no researcher as independent subject - in diffraction the intra-action and connections between human and non-human phenomena are foregrounded. Rather than pondering on the meaning of texts or events, a diffractive methodology focuses on what these phenomena do and what they are connected to (Grosz, 1994). This interconnectedness and relationality between all organisms and matter is important to bear in mind, as the taken-for-grantedness of the coherent ' $\mathrm{I}$ ' in reflexivity needs to be constantly challenged in diffractive methodologies (lenz Taguchi, 2010). To summarize then, Haraway, Barad and education scholars propose a diffractive methodology as a way of troubling dualisms: me and not me, discourse and matter, words and things. As Barad (2014, p. 168) puts it 'diffraction troubles the very notion of dicho-tomy - cutting into two - as a singular act of absolute differentiation, fracturing this from that, now from then'.

A second ground on which reflexivity is considered insufficient is that it does not pay attention to the materiality of data and the entanglements and interdependencies in processes in which 
different kinds of bodies are co-constituted. Barad (2007) outlines a number of differences between reflection and diffraction in her relational ontology which forms the basis for her 'posthumanist performative account of material bodies (both human and nonhuman)'where'a relationality between specific material (re)configurings of the world through which boundaries, properties, and meanings are differentially enacted' (p. 183). she proposes diffraction as a way out of seeing the world from an individualist, humanist and representationalist perspective in which a distinctly separate, atomistic individual man, seen as the 'measure of all things', the centre of the universe is able to reflect from a distance on the world, as is assumed in reflection or reflexivity. From a posthuman perspective, Barad (2007), Braidotti (2013) and snaza and Weaver (2015) see this humanist view of the world as being so deeply rooted in current thought that it is difficult to extricate thoughts from the taken-for-grantedness of the tenets of humanism and of how human subjects are constituted.

Barad (2007) uses poststructural theory, science studies and physics to consider how the cultural and natural come together by diffractively reading them through each other. From this vantage point, the boundaries between humans and both living and non-living others are reconfigured, with all being seen as contributing to change, and as agentive. In this way separateness, interiority and exteriority and the ontological, epistemological and spatial centredness of humans are queered.

Davies (2014a), in her explanation of why she uses a diffractive rather than a reflexive methodology for qualitative research, indicates how a diffractive methodology causes a profound rethinking of the research process (see also Davies \& Gannon, 2013). This process of questioning qualitative research methodology has not come out of nowhere, of course. similar to what stanley and Wise (1983) in the 1980s were already putting forward in the 1980s sofia Villenas (1996), Davies et al. (2004), and Wanda Pillow (2003) to name a few scholars, have already raised important issues with regard to the epistemic privilege of researchers within a reflexivity paradigm of research (see Pillow, 2015 for an in-depth discussion of reflection and reflexivity as well their different modalities and contributions in research methodologies). Davies, in particular, notes that reflexivity represents what exists outside, a pre-existing world, such as an object which is independent of the researcher and can be pinned down by the researcher's gaze. As she observes, reflexivity 'is implicitly based on the phenomenon of a pattern of light that reflects an actual object or entity' (Davies, 2014a, p. 2). While reflection can document difference, diffraction, on the other hand, is a process of producing difference.

\section{Implications of diffractive analysis for research methodology}

We now turn our attention to issues of methodology, focusing in particular on the aspects of diffractive analysis which are particularly useful; and at the same time we wish to acknowledge the contributions that have been made by the paradigm of reflexivity and especially critical reflection. Thus, we agree with the points raised about the value of using diffractive analysis, but we want to avoid setting up a binary between reflection and diffraction. undoubtedly, reflexivity might not have been sufficient for some of the reasons discussed earlier; however, if we want to be fair to the theoretical and methodological developments that have been made over the years, we might need to acknowledge that the 'entanglement' of reflexivity and diffraction is one that includes continuities and breaks rather than a 'story' of one vs. the other. 
First, we need to acknowledge that the concepts of reflection, reflexivity and critical reflection are often used interchangeably, implying that they have the same meaning (Fook \& Askeland, 2006). yet, we need to recognize the nuance in these terms; reflection, reflexivity and critical reflection are not the same thing (Pillow, 2015). Although they are all grounded in the 'ideology of representation' as Woolgar (1988) would say, some forms of reflexivity have covered considerable ground in terms of interrogating the representational paradigm and its consequences.

For example, the notion of critical reflection has been developed and explored over the years, especially in the context of critical theory, poststructuralist and feminist literature, as an approach that recognizes and responds to power structures and relations in reflection processes (Brookfield, 2009; Harding, 1991; Pillow, 2015). Collectively, this work emphasizes that there is something more to critical reflection as an alternative to mere reflection. Critical reflection involves critical thinking about our experiences within their social and political context and also a deeper understanding of how to use this knowledge to improve our practices in the future (Hickson, 2011).

Therefore, we agree with Fook and Askeland (2006) that the distinction among different terms is important enough, if we don't want to fall into the trap of treating these terms in the same manner. Haraway and Barad, correctly in our view, focus their critique on reflexivity (as they are concerned with the wider sociological process of change), whereas some of their followers (e.g. lenz Taguchi, 2012, p. 161) jump from 'reflection' (as a method and metaphor) to 'critical reflection' without making a clear distinction between them. on the other hand, although critical reflection is useful in that it begins to recognize at least the entanglement of issues of power relations in the process of knowing, it is still located in the linguistic turn which foregrounds language and discourse - assuming that reality is constituted through language and that objects and language are separate from each other, thus holding the material world at a distance.

Diffraction moves a step further in that it assumes a direct material engagement and incorporates both things and words - the material-discursive. The primacy of materiality in diffractive analysis is grounded in a solid onto-epistemological framework (Barad, 2007). Diffraction is not constituted as an inner mental activity inside a separated human being; rather it is an interconnected activity that entangles the human and the non-human (Hultman \& lenz Taguchi, 2010). To engage in diffractive analysis means to study the practices of knowing as they are enacted in the materiality of the world, in a state of interdependence with other parts of the world. This onto-epistemological thinking, as Barad (2007) calls it, decentres the researcher as knowing subject and takes us 'beyond the dominating subject/object, human/non-human, as well as the discourse/matter and nature/culture dichotomies' (Hultman \& lenzTaguchi, 2010, p. 539).

Furthermore, a diffractive analysis diverges from a self-reflective, phenomenological or interpretive reading of data, because it moves beyond the representational trap of trying to figure out what a participant really meant by what she or he said (lenz Taguchi, 2012). A diffractive reading of data goes against interpretivism, as interpretation in reflexive analysis is about reflecting sameness (as in mirroring), or identifying differences from something previously identified and acknowledged' a 
thing, an identity, a category, a discursive theme or a subject position' (lenz Taguchi, 2012, p. 269). Difference in interpretivism is grounded in an ontological essentialism between identified categories (man/woman, working class/middle class, white/black, etc.). Rather, a diffractive analysis views difference as a relational ontology, that is, an effect of connections and relations within and between different bodies, affecting other bodies and being affected by them (lenz Taguchi, 2012). Diffraction can then be regarded as an ethical and socially just practice, in that it does not do epistemological damage, pitting one theory/ position/stance against another, but carefully and attentively doing justice to a detailed reading of the intra-actions of different viewpoints and how they build upon or differ from each other to make new and creative visions.

All in all, a turn to diffraction as a metaphor and methodology requires an important ontoepistemological and ethical shift in our thinking so that we begin to take notice of the differences and transformations that emerge in specific events. As Hultman and lenz Taguchi (2010) argue, this will make us investigate and do educational research and write our analyses in a very different way, using quite a different language that is more evocative and perhaps poetic. Choosing to enact a diffractive analysis will also create new opportunities for ethical and political connections and transformations that were previously unimaginable (e.g. new social and interpersonal relations). We end the paper by offering a specific example of how we have used both a diffractive and reflexive methodology as part of our engagements in a research project; this example will make more explicit some of the continuities and breaks between reflection and diffraction.

\section{An example of a diffractive methodology}

The authors of this paper are part of an international research project focusing on critical posthumanism, the affective turn and socially just pedagogies in higher education, which involves academics from a number of differently located higher education institutions as well as Ph.D. students who are studying related topics. The purpose of the project is to explore how theoretical frameworks such as how critical posthumanism could be used to review and renew socially just pedagogies in higher education. In order to familiarize ourselves with the literature on posthumanism, one of the authors and another co-investigator from the project started a reading group, a community of inquiry, where we use a diffractive methodology to intra-act with texts chosen for the reading group, and with each other. some members of the group meet face-to-face while others are online participating from different parts of the world. Google Drive is used to share information and to write notes about the readings and to upload recordings of the discussions. skype and Adobe Connect are used to communicate across different geographical locations. our collaborative research question in the reading group emerged over time into: What is the impact of theoretical ideas such as critical posthumanism and the affective turn on our understandings and practices of socially just pedagogies in higher education?

The group meets regularly and engages with posthumanist/new feminist materialist texts by writers such as karen Barad, Rosi Braidotti, Donna Haraway, Gilles Deleuze and Felix Guattari, and those authors who have applied these theorists in their research and teaching practices, referred to in the earlier part of this paper, such as lenz Taguchi and Maclure. using a philosophical community of inquiry approach (see Murris, 2016; for more details of this) members of the group intra-act with the text chosen for the week (e.g. Barad's (2007) book Meeting the universe Halfway was read each 
week chapter by chapter) and with each other and are encouraged to identify where and how they are interpolated by text - the 'hotspots' which 'glow' for them - sections which are intriguing or disturbing or which are experienced as difficult (Maclure, 2013). Rather than 'explaining' what might be happening when we place two texts together, we attempt to make the texts 'proliferate', that is, to open possibilities of entering new spaces of inventive learning that do not seek to represent the right answer. We alternate between reading methodological texts one week and philosophical/theoretical texts the next. new questions emerge from this sort of reading concerning, for example, how colonialisms, racisms and economies are entangled and act through the appropriation of bodies in university settings around the globe, preventing the materialization of certain socially just pedagogies. The entangled intra-actions in our research group include the emerging questions, the embodied or virtual presence of assembled members, a history of working together as collaborating authors, colleagues and researchers, the physical space of the meeting place and the space of distance communication for those who join the group electronically from around the world, and decisions 'how' to read texts and entangled realities.

The weekly reading group sessions include a small portion of the text to be collectively read out loud by all - both virtual and face-to-face participants, making it possible to pay close attention to the details of the text. Affect moves through voice, language and text among those physically present and those virtually present from a distance. The group develops questions based on Barad's (2007) suggestion regarding diffractive readings - to 'interrupt' our habits of thinking and doing, as 'the world is materialized differently through different practices' (Barad, 2007, p. 89). our habits (as both educators/ researchers and learners) are tied to material-discursive conditions of things, as well as ideas and they are also tied to particular settings and spaces (lenz Taguchi, 2010). A diffractive reading, then, becomes a more-than-representational approach of engaging with the materiality and entanglement of reading; this kind of engagement does not remain within the 'boundaries' of reflective reading which usually focuses on providing 'interpretations' of the texts at hand. Diffractive reading allows us to explore ways of mapping routes of 'reading' through space and time and to create collaborative cartographies that are not merely 'representational'.

Our group is multidisciplinary, incorporating education, fine art, health sciences, physics, engineering, humanities disciplines as well as geopolitically differently positioned higher education institutions. These differences are regarded as affirmative rather than as a lack in the group, as different natural, humanities and social disciplinary perspectives, different higher education contexts, as well as our own different life experiences, theoretical and practical knowledges and histories, constitute useful insights for threading through the readings. These differences and intensities bring into focus the entanglements of disciplinary knowledge-making processes, different life experiences and the effects that these have on the texts. The dis/continuity of face-to-face and online communication across space, place and time is a reminder that phenomena 'are specific ongoing reconfigurings of spacetimemattering' rather than occurring in a particular space and time (Juelskjær \& schwennesen, 2012, p. 12).

What working with diffractive methodology does is to open a space that enables us to see the constitutive force of 'entangled relationalities to make connections between entities that do not appear to be proximate in space and time' (Barad, 2007, p. 74). Thus texts are read across 
geographical distance and across different time zones (Penang, Johannesburg, Cape Town) and across weeks and months intra-act with the writings and practices of the group. We can begin to make legible the diffractive relations between the physically present and those virtually present. Time and space are thus queered in the meetings as participants are intra-acting through conversations on the internet while located in different parts of the world and different time zones. In a diffractive methodology, time is not perceived linearly, and past and present are not sequential. As Barad (2014, p. 169) puts it 'Diffractions are untimely. Time is ... broken apart in different directions, non-contemporaneous with itself'. Past and present, 'presence' in different parts of the world 'are enfolded in the entanglement of intra-activity' (larson \& Phillips, 2013, p. 26). our interest, then, is not whether time-space entanglements create boundaries that limit learning possibilities, but in fact, how these entanglements constitute new openings and possibilities for interrupting our habits of thinking and doing socially just pedagogies in higher education. Google Drive and Google Documents which allow for multiple writers to insert text, write, comment and chat simultaneously across geographical contexts is a useful diffractive tool providing affordances of material entanglements of ideas relationally developed through intraaction with the tools and the writers. Google Docs also shows the trace of all reconfigurations (Barad, 2010) through its history function - previous versions of the document can be revisited and brought to the fore, so that there is no erasure of previous markings. The sessions are also recorded and uploaded onto the group's Google folder for those who missed the sessions.

The reading group sessions provide ongoing and mutually constitutive encounters of entanglements with texts, Ph.D. students, supervisors and other interested participants intra-acting with each other, diffracting ideas which are emergent in the weekly encounters of the collective assemblage, inspiring unpredictable and provocative ways which provide possibilities for new imaginings, for complexity and for creation of the not yet known in writing projects such as special issues of journals and edited collections, as well as Ph.D. projects and other practices of group members. The group members are shifting and not necessarily all involved in the posthumanism research project, and there is also no obligation to attend sessions, however, a sense of commitment and response-ability has developed towards the readings and the other group members. The openness of the community of enquiry approach which leads to a collective imagining for engaging with the readings assists to mitigate against preconceived notions and pitting one theorist, approach or discipline against the other or holding one perspective as foundational. In this way, the community of enquiry is a conducive place for avoiding 'epistemological damage' referred to before in the paper which Barad mentions in her interview with Juelskjæ and schwennesen (2012, p. 13), where ideas are caricatured and knocked down.

To show more specifically the continuities and breaks between these two methodologies - diffraction and reflection - we want to discuss now the example of reflective journals. This tool was used in another research project which both authors have been involved in, focusing on how to engage in socially just pedagogies by bringing participatory parity to the higher education classroom space. This project was thus not focused on posthumanism, but Fraser's $(2008,2009)$ ideas of social justice and how these could apply to higher education teaching and learning. The purpose of asking participants of this research group to write a reflective journal was to ascertain what participants'and facilitators'/teachers'intentions and motives were in relation to practices which encouraged 
participatory parity (the ability to participate as equals) in higher education pedagogy. 6 This reflective journal was derived from edwards (2015), a member of the participatory parity research project, who theorized the development of reflective journals as a research tool for examining the motivations of various groups of people regarding their actions. The theoretical foundations of the tool are cultural historical approaches, and more particularly the work of the activity theorist l'eontev and his notion of object motives for reflecting on people's interpretations of what is important or what matters to them in activities. In other words, this kind of journaling is grounded in a representational mode of learning in which the focus is on the individual, their motives and the constitutive force ascribed to self or interpretation (edwards, 2015).

The intentionality of the educator and participants is paramount in this practice of reflexive journaling, which requires a self-referential engagement, looking back in hindsight on one's own motives and practices. The tool that was used for the process by the facilitators and participants is reflected in Figures 1 and 2.

The reflective journal is predicated on the epistemological belief that it is possible to review one's actions and intentions from a distance, thus it is completed every week in hindsight, reflecting on the previous session and the individual response - to take what Barad $(2007,88)$ would call a'selfreferential' looking back at oneself, one's motives and one's actions towards a particular purpose. The individual subject is therefore seen as the reflexive/reflective agent in this situation (Davies \& Gannon, 2013).

\begin{tabular}{|c|}
\hline Name: \\
\hline $\begin{array}{l}\text { ACTIVITY : Very briefly describe one everyday activity } \\
\text { this week in the identified course/group where you were } \\
\text { aware that you were promoting a socially just pedagogy } \\
\text { (practices that work towards participatory parity) (e.g. the } \\
\text { content of what you are teaching which promotes this or } \\
\text { the processes that you used in your teaching). }\end{array}$ \\
\hline $\begin{array}{l}\text { ACTIONS: What did you do during the activity i.e. what } \\
\text { actions did you take? (e.g. what did you do to facilitate } \\
\text { the students feeling empowered, safe to express } \\
\text { themselves; to ask and respond to peers' questions } \\
\text { without feeling oppressed, domesticated or silenced; to } \\
\text { encourage intellectual freedom to 'think-aloud', 'try-out' } \\
\text { new things and reflect on lessons learnt; to reduce the } \\
\text { psychological distance between knowledgeable others } \\
\text { (peers and experts); to promote an environment in which } \\
\text { learners are equal partners in knowledge production } \\
\text { (participatory parity). You can mention as many actions } \\
\text { as you like. }\end{array}$ \\
\hline $\begin{array}{l}\text { AIMS: What are the long term strategic goals behind how } \\
\text { you worked with students in this activity? How do your } \\
\text { actions in this activity relate to these goals? }\end{array}$ \\
\hline
\end{tabular}

Figure 1. Reflexive journal for facilitators. Questions for collecting reflexive data on ourselves. 
Furthermore, the binary of the facilitator and the participants is also assumed in these journals which have different journal exercises for educators and Ph.D. students assuming that their practices are different. Although we found it interesting to review each others' reflexive journals each week and to gain insights from what people in the group were retrospectively writing, and make changes to our practices, we recognized the limitations of merely 'representing' what we thought our intentions were, rather than engaging directly with the texts, with each other and the materiality of group intra-actions.

\begin{tabular}{|l|}
\hline ACTIVITY : Very briefly describe one activity in the last \\
week in the designated sessions where you felt \\
empowered, safe to express yourself; to ask and \\
respond to peers' questions without feeling oppressed, \\
domesticated or silenced; where you felt encouraged \\
with the intellectual freedom to 'think-aloud', 'try-out' new \\
things and reflect on lessons learnt; where you felt that \\
the psychological distance between knowledgeable \\
others (peers and experts) in your group was lessened or \\
reduced; where you felt that you were in an environment \\
in which you as a learner was an equal partner in \\
knowledge production (participatory parity). \\
How did the following things impact on your experience: \\
the resources you had access to do the task, \\
the ways in which your attributes (e.g. cultural \\
background and knowledge) were valued/devalued, \\
where you felt you either had a voice and your \\
contributions were shared/had an impact on others or \\
that this was not the case
\end{tabular}

Figure 2. Reflexive journal for participants.

One of the observations that was mentioned in a journal entry was that participatory parity is difficult across geographical locations in that the face-to-face intra-actions between members in the flesh, were more satisfactory than the online ones, despite attempts being made to be as inclusive as possible. The internet sometimes was unstable, members were kicked on and off the platform, creating difficulties for participatory parity. 
The collective diffractive methodology used in our multiple reading group encounters was different from these journal entries, which required an individual perspective rather than an intra-active relational one, a position of distance and hindsight from the group rather than the understanding that we are part of, entangled and implicated in everything happening in the group and the material world. What working with diffractive methodology did was to open this space further to enable us to see that it is not the (reflexive) self that has constitutive force, but self and others (social and material elements), entangled in multiple ways and across multiple spaces and times. To learn diffractively, we had to unlearn our drive to engage in a reflective process focused on the self or searching for interpretations, as this suppressed the alternative possibilities that we might have come up with opening up to the ontology of learning - e.g. paying attention to the entangling of bodies, ideas, flows and intensities generated by our collaboration in the spaces of a physical setting, yet across the internet all over the globe.

It would be interesting to engage in how to refashion the reflexive journal into a dialogical intraactive diffractive journal where ideas, bodies and texts encounter each other, forming interferences which matter and which build on each other, creating new productive visions (Davies, 2014a; Dolphijn \& van der Tuin, 2012). An important observation though is that the guiding/reflective questions sit neatly in a judgmental framework, as pointed out earlier, equated with what Deleuze (1988) calls moralism, whereas diffraction sits much more neatly with Deleuzian ethics (Davies, 2014a).7 Whereas morality judgesagainst anideal and finds each person wanting, ethics asks rather 'what is it to bethis?'

What we hope to have made legible by focusing on the example of reflexive journals is the way in which the process of reflection can become a diffractive apparatus, if it begins to pay attention to the diffractive entanglements of the ontological, epistemological and ethical dimensions of life and the entangled enlivening of being (Davies \& Gannon, 2013). The reflexive process assumes a human agency that works alone and intentionally; the diffractive process instead acknowledges that individual agency is entangled with other agencies, and this realization has important ethical and material implications that must be examined. In thinking about these processes through our research practices, we have become aware that it is important to remember that these practices are not something to be read about or applied, but they are better approached as social-material becomings, knowings through beings entangled through and with other objects and beings.

\section{Conclusion}

This paper has taken the debate regarding the intersections and differences of diffraction and reflection as metaphors and methodologies further, particularly with respect to educational practice and research. We have noted that both methodologies acknowledge the situatedness of knowledge, and offer a more enlarged perspective of the research process. Diffraction alerts us to the entanglement of the apparatus in addition to the embedded and embodied researcher, who is seen as part of the world. Diffraction provides additional affordances through its connection of the discursive and the material, with knowledges making themselves intelligible to each other in creative and unpredictable ways. Barad's (2007) combination of the onto-ethico-epistemological revitalizes the research process, making it methodologically powerful through its enlarged vision 
of making a difference in the world with ethics being an integral part of it (Mazzei, 2014, p. 743). one of the important propositions that this paper makes is that diffraction is an affirmative methodology which has a great deal to offer for reconfiguring liberal humanist practices used in research methodology.

Although diffraction and reflection differ both as methodologies and as practices, being grounded in different ontologies, epistemologies and ethics, there is some continuity in the historical development of ideas from one to the other (see e.g. Campbell's (2004) discussion of Haraway's notions of reflexivity and diffraction). This paper emphasizes the prospects of the notion of diffraction as a tool of analysis, for attentive and detailed reading of a text intra-actively through another for the consequential differences that matter. It is suggested that a diffractive analysis goes beyond the idea of reflexivity and interpretation and produces new entangled ways of theorizing and performing research practices, co-constituting new possibilities of strengthening and challenging knowledges. The time has come for educational researchers to reconsider the metaphor and methodological implications of reflection and explore the ethico-ontoepistemological potentiality of diffraction in the historical continuities and breaks with the traditions of reflection.

\section{Notes}

1. simply stated, the physical phenomenon diffraction is unique to waves - such as water, sound and light waves.

Diffraction refers to the behaviour of waves which combine when they overlap, and bend and spread out when they encounter an obstacle (see Barad, 2007, pp. 74-85 for an extended explanation). In contrast to reflecting apparatuses (e.g. mirrors), which produce images, which are more or less faithful to the objects placed in front of them, thus producing sameness, diffraction patterns mark differences in the relative characters (i.e. amplitude and phase) of individual waves as they combine.

2. Pillow (2003) located 'reflection' as arising from a philosophical, Deweyian ideal of'to look back over", while locating 'reflexivity' and 'self-reflexivity' out of the social sciences. she also made the distinction that to be 'reflective' does not demand an 'other", whereas to be 'reflexive' demands both an other and some form of self-awareness (see also Pillow, 2015).

3. See also Denzin (1997) and Davies et al. (2004) for a discussion on theoretically contradictory forms of reflexivity.

4. As one of the anonymous reviewers points out, this argument resonates with sedgwick's (2003) discussion of reparative (vs. paranoid) readings. Reparative reading according to sedgwick is a critical practice that seeks repair of what may be broken. Reparative position, though, is not merely a critical practice of 'making visible [...] the hidden traces of oppression and persecution' (sedgwick, 2003, p. 141), but it is affectively driven and 'undertakes a different range of affects, ambitions, and risks'(sedgwick, 2003, p. 150). Diffractive methodology, then, might be perceived as a form of reparative practice that highlights provocations and takes risks rather than hiding differences.

5. According to Barad (2007) phenomena are the intra-acting material-discursive configurations constituted by the agential cuts of apparatuses. 
6. The notion of participatory parity as a socially just practice is based on the work of Fraser (2008, 2009), who identified the importance of economic, cultural and political dimensions for social justice or participatory parity.

7. We are indebted to one of the anonymous reviewers for suggesting this idea.

\section{Disclosure statement}

No potential conflict of interest was reported by the author.

\section{Funding}

This work was supported by South African national Research Fund [87731].

\section{Notes on contributors}

Vivienne Bozalek is a professor of social Work and the Director of Teaching and learning at the University of the Western Cape, South Africa. Her research interests include new materialism, the ethics of care and social justice and their applications to higher education and other fields of practice. She is currently involved in research projects which focus on socially just pedagogies in higher education.

Michalinos Zembylas is an associate professor of educational Theory and Curriculum studies at the open university of Cyprus. He is also a visiting professor and a research fellow at the Institute for Reconciliation and social Justice, university of the Free state, south Africa. He has written extensively on emotion and affect in relation to social justice pedagogies, intercultural and peace education, human rights education and citizenship education. 


\section{References}

Archer, M. s. (2003). Structure, agency and the internal conversation. Cambridge: Cambridge university Press.

Archer, M. s. (2007). Making our way through the world: Human reflexivity and social mobility. Cambridge: Cambridge university Press.

Archer, M. s. (ed.). (2010). Conversations about reflexivity. london: Routledge.

Barad, k. (2007). Meeting the universe halfway: Quantum physics and the entanglement of matter and meaning. Durham: Duke university Press.

Barad, k. (2010). Quantum entanglements and Hauntological relations of inheritance: Dis/continuities, spacetime enfoldings, and justice-to-come. Derrida Today, 3, 240-268.

Barad, k. (2014). Diffracting diffraction: Cutting together-apart. Parallax, 20, 168-187.

Barad, k. (2015). TransMaterialities: Trans*/matter/realities and queer political imaginings. GLQ: A Journal of Lesbian and Gay Studies, 21, 387-422.

Beck, u. (1992). Risk society. london: sage.

Beck, u. (1994). Ecological enlightenment: Essays on the politics of the risk society. Amherst, ny: Prometheus Books.

Bradbury, H., Frost, n., kilminster, s., \& Zukas, M. (eds.). (2010). Beyond reflective practice: New approaches to professional lifelong learning. new york, ny: Routledge.

Braidotti, R. (2013). The Posthuman. Cambridge: Polity Press.

Brookfield, s. (1995). Becoming a critically reflective teacher. san-Francisco, CA: Jossey-Bass.

Brookfield, s. (2009). The concept of critical reflection: Promises and contradictions. European Journal of Social Work, 12, 293-304.

Campbell, k. (2004). The promise of feminist reflexivities: Developing Donna Haraway's project for feminist science studies. Hypatia, 19, 162-182.

D'Cruz, H., Gillingham, P., \& Melendez, s. (2007). Reflexivity, its meanings and relevance for social work: A critical review of the literature. British Journal of Social Work, 37, 73-90.

Daley, A. (2010). Reflections on reflexivity and critical reflection as critical research practices. Affilia, 25, 68-82. Davies, B. (2014a). Listening to children: Being and becoming. london: Routledge.

Davies, B. (2014b). Reading anger in early childhood intra-actions: A diffractive analysis. Qualitative Inquiry, 20, 731-741. http://dx.doi.org/10.1177/107780041453025

Davies, B., Browne, J., Gannon, s., Honan, e., laws, C., Mueller-Rockstroh, B., \& Bendix Petersen, e. (2004). The ambivalent practices of reflexivity. Qualitative Inquiry, 10, 360-389.

Davies, B., De schauwer, e., Claes, l., De Munck, k., Van De Putte, I., \& Verstichele, M. (2013). Recognition and difference: A collective biography. International Journal of Qualitative Studies in Education, 26, 680-691. doi: http://dx.doi.org/10.1080/09518398.2013.788757

Davies, B., \& Gannon, s. (2013). Collective biography and the entangled enlivening of being. International Review of Qualitative Research, 5, 357-376.

Deleuze, G. (1988). Spinoza: Practical philosophy. san Francisco, CA: City lights Books.

Denzin, n. (1997). Interpretive ethnography: Ethnographic practices for the 21st century. Thousand oaks, CA: sage. Dolphijn, R., \& van der Tuin, I. (2012). New materialism: Interviews \& cartographies. Ann Arbor, MI: new Humanities Press. edwards, A. (2015). A tool for public services research and development. International Journal of Public Management, 11, 21-33. 
Edwards, G., \& Thomas, G. (2010). Can reflective practice be taught? Educational Studies, 36, 403-414. elliott, A. (2002). Beck's sociology of risk: A critical assessment. Sociology, 36, 293-315.

Fendler, 1. (2003). Teacher reflection in a hall of mirrors: Historical influences and political reverberations. Educational Researcher, 32, 16-25.

Fook, J. (2002). Social work: Critical theory and practice. london: sage.

Fook, J., \& Askeland, G. (2006). The "critical" in critical reflection. In s. White, J. Fook, \& F. Gardner (eds.), Critical reflection in health and welfare (pp. 40-53). Maidenhead: open university Press.

Fook, J., \& Gardner, F. (2007). Practicing critical reflection: A resource handbook. london: open university Press.

Fraser, n. (2008). Reframing justice in a globalizing world. In k. olson (ed.), Adding insult to injury: Nancy Fraser debates her critics (pp. 273-291). london: Verso.

Fraser, n. (2009). Scales of justice: Reimagining political space in a globalizing world. new york, ny: Columbia university Press. Gentles, s., Jack, s., nicholas, D., \& Mckibbon, A. (2014). A critical approach to reflexivity in grounded theory. The Qualitative Report, 19, 1-14.

Giddens, A. (1990). The consequences of modernity. Cambridge: Polity.

Giddens, A. (1991). Modernity and self-identity: Self and society in the late modern age. stanford, CA: stanford university Press. Gray, B. (2008). Putting emotion and reflexivity to work in researching migration. Sociology, 42, 935-952.

Grosz, e. (1994). A thousand tiny sexes: Feminism and rhizomatics. In C.V. Boundas \& D. olkowski (eds.), Gilles Deleuze and the theater of philosophy (pp. 187-210). New York, NY: Routledge.

Haraway, D. (1991). A cyborg manifesto: science, technology, and socialist-feminism in the late twentieth century.

In D. Haraway (ed.), Simians, cyborgs and women: The reinvention of nature (pp. 149-181). new york, ny: Routledge. Retrieved from http://faculty.georgetown.edu/irvinem/theory/Haraway-CyborgManifesto.html

Haraway, D. (1992). The promises of monsters: A regenerative politics for inapproporiate/d others. In l. Grossberg, C. nelson, \& P. A. Treichler (eds.), Cultural studies (pp. 295-337). new york, ny: Routledge.

Haraway, D. (1997).Modest_Witness@Second_Millenium: FemaleMan_Meets_OncoMouse : Feminism andTechnoscience. new york, ny: Routledge.

Haraway, D. (2000). How like a leaf: An interview with Thyrza Nichols Goodeve. new york, ny: Routledge.

Harding, s. (1991). Whose science? Whose knowledge? Thinking from women's lives. Milton keynes: open university Press. Harding, s. (1996). Rethinking standpoint epistemology. What is "strong objectivity"? In e. Fox keller \& H. e. longino (eds.), Feminism and science (pp. 238248). oxford: oxford university Press.

Harrison, J. k., \& lee, R. (2011). exploring the use of critical incident analysis and the professional learning conversation in an initial teacher education programme. Journal of Education for Teaching, 37, 199-217.

Hickson, H. (2011). Critical reflection: Reflecting on learning to be reflective. Reflective Practice, 12, $829-839$.

Hoel, A. S., \& van der Tuin, I. (2012). The ontological force of technicity: Reading Cassirer and simondon diffractively. Philosophy \& Technology, 26, 187-202. 
Holmes, M. (2010). The emotionalization of reflexivity. Sociology, 44, 139-154.

Hultman, k., \& lenz Taguchi, H. (2010). Challenging anthropocentric analysis of visual data: A relational materialist methodological approach to educational research. International Journal of Qualitative Studies in Education, 23, 525-542. Jackson, A. y., \& Mazzei, 1. A. (2012). Thinking with theory in qualitative research: Viewing data across multiple perspectives. london: Routledge.

Juelskjaer, M. (2013). Gendered subjectivities of spacetimematter. Gender and Education, 25, 754768.

Juelskjær, M., \& schwennesen, n. (2012). Intra-active entanglements: An interview with karen Barad. Kvinder, Koen og Forskning, 21, 10-23.

Kleinman, A. (2012). Intra-actions. Mousse, 34, 76-81.

Korthagen, F., kessels, J., koster, B., lagerwerf, B., \& Wubbels, T. (2001). Linking practice and theory: The pedagogy of realistic teacher education. Mahwah, nJ: lawrence erlbaum Associates.

Larson, M., \& Phillips, D. (2013). searching for methodology: Feminist relational materialism and the teacher-student writing conference. Reconceptualizing Educational Research Methodology, 4, 19-34.

Latour, B. (2004). Why has critique run out of steam? From matters of fact to matters of concern. Critical Inquiry, 30, 225-248. lenz Taguchi, H. (2010). Going beyond the theory/practice divide in early childhood education: Introducing an Intra-active pedagogy. london: Routledge.

Lenz Taguchi, H. (2012). A diffractive and Deleuzian approach to analysing interview data. Feminist Theory, 13, 265-281. lenz Taguchi, H. (2013). Images of thinking in feminist materialisms: ontological divergences and the production of researcher subjectivities. InternationalJournal ofQualitative StudiesinEducation, 26, 706-716.

Lenz Taguchi, H., \& Palmer, A. (2013). A more 'livable' school? A diffractive analysis of the performative enactments of girls' ill-well-being with(in) school environments. Gender and Education, 25, 671-687.

lyons, n. (ed.). (2010). Handbook of reflection and reflective inquiry: Mapping a way of knowing for professional reflective inquiry. Dordrecht: springer.

Maclure, M. (2013). Classification or wonder? Coding as an analytic practice in qualitative research. In R. Coleman \& J. Ringrose (eds.), Deleuze and research methodologies (pp. 164184). edinburgh: edinburgh university Press.

Mezirow, J. (1990). How critical reflection triggers transformative learning. In J. Mezirow (ed.), Fostering critical reflection in adulthood: A guide to transformative emancipatory learning (pp. 1-20). san Francisco, CA: Jossey-Bass.

Mazzei, 1.A. (2014). Beyond an easy sense: A diffractive. Qualitative Inquiry, 20,742-746.

Moon, J. (1999). Learning journals: A handbook for academics, students and professional development. london: kogan Page.

Mruck, k., \& Mey, G. (2007). Grounded theory and reflexivity. In Anthony Bryant \& kathy Charmaz (eds.), The Sage handbook of grounded theory (pp. 487-510). london: sage.

Murris, k. (2016). The Posthuman child: Educational transformation through philosophy with picturebooks. london: Routledge Contesting early Childhood series. 
Palmer, A. (2011). "How many sums can I do?" Performative strategies and diffractive thinking as methodological tools for rethinking mathematical subjectivity. Reconceptualizing Educational Research Methodology, 1, 3-18.

Phillips, D. k., \& larson, M. l. (2012). The teacher-student writing conference entangled: Thinking data with material feminisms. Cultural Studies $\leftrightarrow$ Critical Methodologies, 12, 225234.

Phillips, D. k., \& larson, M. l. (2013). The teacher-student writing conference reimaged: entangled becoming-writingconferencing. Retrieved from http://digitalcommons.linfield.edu/educfac_pubs/8

Pillow, W. (2003). Confession, catharsis, or cure: Rethinking the uses of reflexivity as methodological power in qualitative research. International Journal of Qualitative Studies in Education, 16, $175^{-196 .}$

Pillow, W. (2015). Reflexivity as interpretation and genealogy in research. Cultural Studies <-> Critical Methodologies, 15, 419-434.

Pollard, A. (2002). Reflective teaching: Effective and evidence-informed professional practice. london: Continuum.

Rouse, J. (1996). Engaging science: How to understand its practices philosophically. Ithaca and london: Cornell university Press.

Schneider, J. (2002). Reflexive/diffractive ethnography. Cultural StudiesCritical Methodologies, 2, $460-482$.

Sedgwick, e. (2003). Touching feeling: Affect, pedagogy, performativity. Durham \& london: Duke university Press.

Snaza, n., \& Weaver, J. (2015). Introduction: education and the posthumanist turn. In n. snaza \& J. Weaver (eds.), Posthumanism and educational research (pp. 1-14). london: Routledge.

Stanley, l., \& Wise, s. (1983). Breaking out: Feminist ontology and epistemology. london: Routledge.

Villenas, s. (1996). The Colonizer/Colonized Chicana ethnographer: Identity, Marginalization and Co-optation in the Field. Harvard Educational Review, 66, 711-732.

Woolgar, s. (1988). Knowledge and reflexivity: New frontiers in the sociology of knowledge. london: sage.

Zeichner, k. M., \& liston, D. P. (1996). Reflective teaching: An introduction. Mahwah, nJ: lawrence erlbaum Associates. Zembylas, M. (2014). The place of emotion in teacher reflection: elias, Foucault, and 'Critical emotional Reflexivity'. Power \& Education, 6, 210-222. 